\title{
Entrevista com o Dr. Luiz Simões Lopes
}

A Fundação Getulio Vargas, criada em 1944, muito cresceu ao longo dos seus 40 anos de existência.

Como se vê no organognama a seguir, ela mantém: o Instituto Brasileiro de Economia (IBRE), que se desmembra em dois grandes setores: A Escola de Pós-Graduaçấo em Economia (EFGE) e o Setor de Pesquisas Económicas; o Instituto de Estudos Avançados em Educaç̄o (IESAE); O Instituto de Direito Público e Cléncia Politica (INDIPO) , o Instituto de Documentafäo (INDOC): O Instituto de Recursos Humanos (IRH); o Instituto Superior de Estudos Contábeis (ISEC), e o Instituto Superior de Estudos e Pesquisas Psicossociais (ISOP). No setor de ensino da administraçāo, mantém trếs principais estabelecimentos: a Escola de Administraçäo de Empresas de Săo Paulo (EAESP); a Escola Brasileira de Administrafäo Pública (EBAP); a Escola Interamericana de Administração Pública (EIAP), esta em regime de convênio com o BID; mantém, ainda, o Centro Interamericano de Comercializaģăo (ClCOM), em regime de acordo com a Organizaçáo dos Estados Americanos eo Ministerio das Relagões Exteriores, e os cursos, de curta duraçāo: de administraçāo de empresas (CADEMP) e os ministrados sobre diversas disciplinas no IRH, no ISOP, no IESAE, no INDOC e no INDIPO.

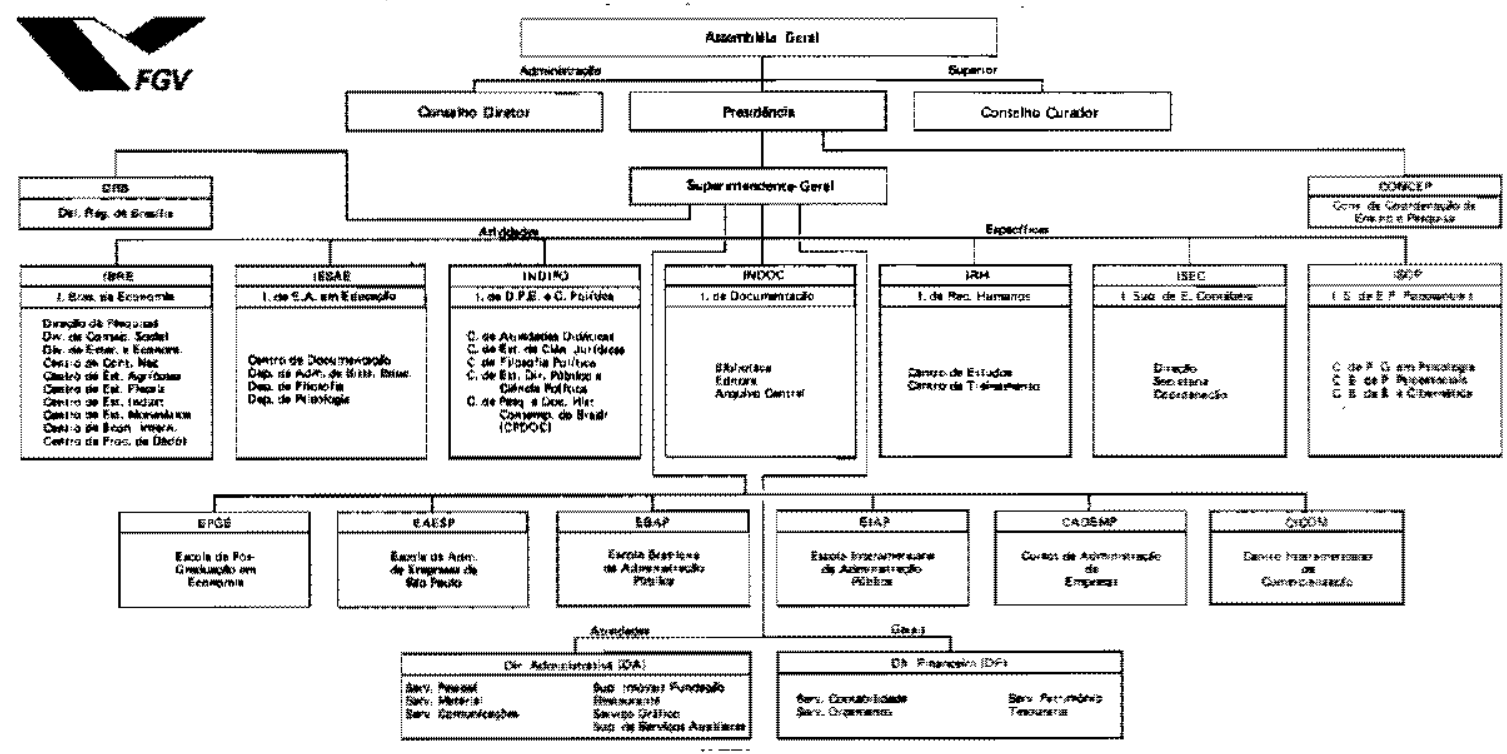

A Escola de Administraça de Empresas de Săo Paulo da Fundaçäo Getulio Vargas completa, em 1984, 30 anos de existência. Gozamos do raro privilégio de poder fixar as bases de nossa historia institucional pela palavra daquele que criou a Fundaçäo ha 40 anos $e$, desde entäo, como seu presidente, tem-se dedicado à sua expansäo em diferentes unidades, entre as quais esta Escola. Representando a memónia viva näo só da trajetónia da Fundaç̄o e da Escola, mas de meio século da histónia da administraçäo no contex to mais amplo da evolucto do Pats e da sociedade brasileira, o Dr. Luiz Simöes Lopes concedeu à $R A E$ a presente entrevista.

A redaçấo do RAE sentesse muito honnda em poder transmitir aos seus leitores, atrovés dessa entrevista, a forte impressāo que experimentam todos os que têm oportunidade de conhecer este homem, sua força, sua coragem e sua vis̄̈o de vanguarda.

1. RAE - Como surgiu a idéia de criar uma instítuição do tipo da FGV, tầo original em relaçã̃o à mentalidade e às práticas de gestão da época?

LSL - A Resoluçä́o de 1930 encontrou a administração federal cheia de vícios, resultantes do regime do "pistolāo" até entäo adotado para o provimento dos cargos públicos. As nomeaçós eram reservadas à clientela politica e, na maioria dos casos, noo recaía em pessoas devidamente habilitadas ao eficiente exercicio das funçdes do Estado. E sem um servico público eficiente e insuspeito não é possivel administrar e. 
conseqüentemente, bem governar o pais. Em 1936, tive a honra de presidir uma Comissto de Reforma Administrativa, que canchu seus estudos apresentando ao presidente da Republica um projeto que, encaminhado ao Congresso, foi convertido na Lei $n^{0} 284$, daquele ano. A Lei $n$ ? 284 classificou os cargos públicos com os respectivos padroes de vencimentos, estabeleceu o sistema do merito para o seu preenchimento e criou o Conselho Fedenal do Servico Piblico Civil, do qual fui nomeado presidente, A Constituictoto de 1937 criou um órgăo na Presidência da

A Constituiçấo de 1937 criou um órgto na Prestdencia da República, que substituiu o citado Conselho: o Departamento Administrativo do Serviço Público (DASP). Este órgto, incumbido de proceder à reforma da administracto federal, consolidou a aplicaça do sistema do merito, atrovés da generalizagffo dos concursos para o ingresso no Serviço Público e da promoçro do aperfeiçoamento técnico dos funciondrios em cursos especializados no pals e no exterior.

o Dasp, com a atribuiça constitucional de determinar do ponto de vista da eficiencia as modificaçóes a serem feitas na organizaçẽo do servifo püblico, de elaborar o Orfamento Geral da República e, de conformidade com as instruföes do presidente da República, fiscalizar a execugfäo orçamentária, teve no periodo de recesso parlamentar de 1937 a 1945 oportunidade de enfrentar tremendas deficiencias dos serviços govemamentais, que tentau corrigit ou elimina por uma serie de medidas saneadoras, fundadas, principalmente, na racionalizaço do trabalho.

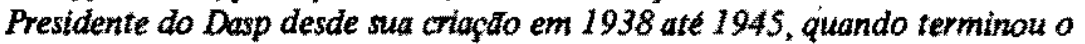
primeiro gaverno do Presidente Getúlio Vargas, tive ocasiz̄o de verificar que póde ser aproveitada apenas uma parcela correspondente a $10 \%$ dos 200 mil candidatos entio submetidos à concurso. Este fato demonstrava tanto a falta de preparo básico da maioria dos candidatos como, do mesmo tempo, as falhas do sistema educacional na formação de pessoal especializado.

Para algumas funçōes técnicas näo havia formação de profissionais habilitados, como, por exemplo, economistas e administradores.

Despendemos imensos esforços para reorgenizar o serviço publico. Mas perdu-

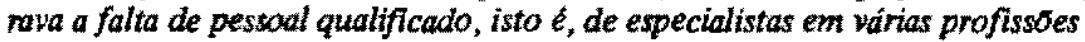
indispensáveis a uma administração moderna, tanto no setor público como no setor privado.

Para assegurar o êxito das reformas em marcha, e das que seriam naturalmente intensificadas com o pos-guerra, que se avizinhava, tomou-se necessdrio, li pelos idos de 1944, criar uma entidade pioneira, de ensino e pesquisa, capaz de preparar o pessoal destinado ao desenvolvimento econômico e social do pats.

Imaginou-se, entāo, a criaçä́o de uma entidade independente, de direito privado, porém subvencionada pelo Governo, dadas as suas finalidades de interesse público, $A$ forma que nos pareceu mais adequada à personalidade juridica dessa entidade foi a Fundacfo prevista no ant, 24 do Código Civil.

o Presidente Getulio Vargas, a quem tive a honra de propor fal iniciativa, aprovou-a gentrosamente e fixou os encargos governamentais relativos d sua concretização e manutenção.

Surgiu, assim, a Fundação, que, por deliberaçäo unanime de seus 305 doadores iniciais, em escritura pública, recebeu o nome de set patrono.

Os membros de sua Administraçäo Superior, isto é, o seu presidente es componentes da Assemblèia Geral, do Conselho Diretor e do Conselho Curador näo to remunerados; trabalham gratuitamente, com o unico objetivo de prestar servicos d instituicto e, atraves dela, wo Brasil.

Cabe perguntar: $E$ os resultados? Não nos compete fulgar a obra realizada pela FGV em seus 40 anos de esforgos inauditos para atingir seus objerivos estatutários. Mas, podemos afirmar que ela goza de credibilidade e procura comesponder à confianco do Pais, sem o que näo poderia ter sobrevivido às graves crises politicas que atravessamos. Os Governos e o püblico em geral acreditam em nossos bons propositos e nos têm dado seu indispensdvel apoio durante esse longo tempo.

2. RAE - No Brasil, não é comum a sobrevivência de uma instituição privada de ensino e pesquisa durante 40 anos. Quais as dificuldades e apoios que acompanharam essa história?

LSL - De fato, näo é comum a sobrevivência churante tão largo tempo de uma instituiçäo como a Fundacto Genulio Vargas. A conclusäo logica é que ela tem servido bem 20 pats.

As matores dificuldades que ela tem enfrentado wo as originarias da crise financeira mundial, que tambem afeta o Brasil. Temos tido, porem, como foi dito, o apoio do 
Govemo e de particulares, o que tem assegurado a continuidade dos nossas esforcos ate agore.

3. RAE - Qual a conjuntura atual da Fundaçzo Getulio Vargas e que perspectivas futuras o Sr. vislumbra para ela?

LSL - Tudo é diffell em um par's submetido a uma inflaço tōo alta. Temos porém esperanca de melhores dias e, por conseguinte, de melhores condiçtes para que a Fundaço possa continuar a desenvolver seus trabalhos.

4. RAE - Mais especificamente em relaçăo à Escola de Sto Paulo, qual foi o plano inicial, o relacionamento com os diversos niveis governamentais e instituiçces privadas, o intercâmbio com os EUA, etc.?

LSL - Se um dos objetivos principais da Fundacto era a formasto de administradores públicos e privados, a criaçăo de uma grande escola de administraçäo de empresas se impunha. Naturalmente, Sżo Paulo, o maior centro empresarial do Brasil e da America Latina, foi escolhido para a sede ideal de uma escola desse genero. No Rio ja funcionava a Escola Brasileira de Administragto Puiblica e, em Sä Paulo, o Govemo e o povo acolheram e têm apolado a nossa EAESP, de que tanto nos orgulhamos, como um grande centro de exceléncia, pela qualidade do ensino, pela competência do professorado, pelo largo renome adquirido no pats e no estrangeino. Devemos reconhecer que para isso concorreram principalmente dois fatores: 0 aperfeicoamento dos seus professores no estrangeiro (particularmente nos EUA) e a excelente colaboraço do Govemo americano, que manteve uma grande e otima equipe de professores curante longos anos em nossa Escola. A EAESP, evidentemente, muito lucrou com essas aluas medidas. Como nto somos ingratos com aqueles que nos ajudam, fizemos questro de testemunhar nossa gratidäo, publicamente, colocando na entrada do ediffio da Escolo o busto do Presidente Kennedy. Foi ele quem concebeu e executou o Plano da Aliança para o Progresso, do qual muito se beneffciaram a Fundaçäo Getulio Vargas e outras instituigtos culturais dos paises latino-americanos.

5. RAE - Como se coloca hoje a sobrevivência da Escola de Administraçăo de Empresas de São Paulo, nos niveis de excelência que sempre a caracterizaram, e quais as condiçoes necessáras para um aprimoramento num futuro proximo?

LSL - A sobrevivência da EAESP posso dizer que está assegurada, pelo renome que adquiriu, pelo grande numero de seus ex-alunos que ocupam funçbes de relevo na vida pública e empresarial de Säo Paulo, pela boa gesta dos seus dirigentes e porque, até do ponto de vista financeiro, pode considerar-se uma Escola auto-suficiente. Aprimorá-la é dever de todos nós: dirigentes da FGV e da Escola; dos membros do seu Conselho da Administraçdo; dos seus professores, alunos e ex-alunos; dos empresdrios, que se beneficiam do concurso da notdvel equipe de administradoras que ela constituiu em Säo Paulo, Não faltaräo, estou certo, forças positivas que hđo de aprimord-la cada vez mais.

6. RAE - A biografia do Sr. praticamente se confunde com a história da Fundação Getulio Vargas. Como o St, se sente em relaça a isso?

LSL - Quando nasceu a Fundacto Getulio Vargas eu jd tinha uma longa vida de trabalho em outros setores, tambem absorventes. A imensa tarefa conclutda, até hoje, pela Fundaçó nö́ é obra minha, mas sim do conjunto de pessoas altamente dedicadas d̀ carsa pública que consegul reunir para organizá-la, conduzi-la e aperfeiçodita.

De fato, grande parte da minha vida tem sido dedicada a este empreendimento. Entre concebe-la, institulta, vencer as imimeras dificuldades que se antepuseram ao nosso profeto, passaram mais de 40 anos. Mas a Fundaço está de pe; Deus me permitiu realizar este sonho magnifico; se muito lutei por esta Casa e nesta Casa envelheci. tentho tido, tambem, grandes sat isfaçбes pessoais por todas as nossas realizaços, como a EAESP, por exemplo.

Espero que Deus me de forças para continuar a ver a Fundaçäo Getulio Vargas em franco progresso, pois muito há que fazer ainda. Como seu presidente ou simples soldado desta cruzada, quero servi-la ate ofim dos meus dias. 